\title{
Gloria Posada, una voz suave y CONSTANTE*
}

\author{
Gloria Posada, a Sweet Constant Voice
}

\footnotetext{
* Cómo citar esta entrevista: Vergara Aguirre, A. (2021). Gloria Posada, una voz suave y constante. Estudios de Literatura Colombiana 49, pp. 245-259. DOI: https://doi. org/10.17533/udea.elc.n49a14

1 https://orcid.org/0000-0002-5304-6550 andres.vergaraa@udea.edu.co

Universidad de Antioquia, Colombia
}

Editores: Andrés Vergara Aguirre, Christian Benavides Martínez

Recibido: 14.05 .2021

Aprobado: 21.05.2021

Publicado: 30.06 .2021

Copyright: (02021 Estudios de Literatura Colombiana. Este es un artículo de acceso abierto distribuido bajo los términos de la Licencia Creative Commons AtribuciónNo comercial - Compartir igual 4.0 Internacional

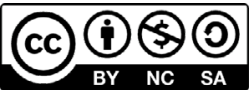

Andrés Vergara Aguirre ${ }^{1}$

Gloria María Posada Vélez, o Gloria Posada, como aparece en las carátulas de sus libros, para más señas la hija de don Ricardo, a quien yo conocía desde mucho antes de que ella publicara su primer libro; un día nos encontramos en un recital, en un encuentro no concertado, y todavía recuerdo la cara de orgullo de don Ricardo cuando me dijo que se trataba del recital de su hija, y me la presentó, en el auditorio de la Cámara de Comercio de Medellín. ¡Qué años aquellos!

Y si hago evocación de la aquella escena, que nadie más tendría por qué recordarla hoy, es porque por alguna parte debemos comenzar, pero es también porque desde entonces, sin haber tenido nunca mucha cercanía con Gloria, de alguna manera siempre he sido testigo de su trayectoria, y nos hemos seguido cruzando, o más bien sus versos se han seguido cruzando con mi oficio de periodista y con mi ejercicio de lector. $Y$ al evocar su trayectoria pienso ahora que ella, su voz de poeta, ha estado presente, como una cantinela suave pero siempre constante. Quien la vea pasar por ahí, con su caminar liviano y sus gestos suaves - "es pequeña y frágil y parece suspendida en el aire", la ha definido 
acertadamente otro poeta de la levedad, Elkin Restrepo (2013, p. 379)—, tal vez no advierta que esa transeúnte es la misma poeta que logra descender hasta grandes profundidades para traernos versos labrados con la paciencia de quien asume el quehacer poético como un Oficio Divino, a propósito de su primer libro, que fue recibido con entusiasmo por el poeta Jaime García Maffla, el mismo que, como integrante de un jurado conformado también por los poetas Giovanni Quessep y Juan Manuel Roca, le había concedido el primer lugar en el Premio Nacional de Poesía Joven, de Colcultura, en 1992. De aquella obra, García Maffla (2013) dijo:

La autora ha trazado lazos con lo poético en hondura y delicadeza impares, si la delicadeza es también comprensión e interpretación de la experiencia humana toda. Hay dolor, como la trascendencia; está en la condición dada al oficio, y a la mano que del aire va a la letra. Y he [sic] decirlo al fin: pocas, muy pocas voces como la suya en Hispanoamérica (p. $38 \mathrm{I})$.

Después de aquella primera obra, con la que Gloria entró pisando firme en el ámbito de la poesía colombiana, al recibir el salvoconducto de tres de los más connotados poetas del país, en 1993 presentó su segunda obra, Vosotras, en la cual desde su voz femenina entabla un diálogo con las mujeres de la historia y de la mitología, al traerlas al presente a través de sus evocaciones. Al presentar esta obra en la colección Autores Antioqueños de la Gobernación de Antioquia, Elkin Restrepo (2013) manifestó su asombro: "Por primera vez, en la poesía colombiana, una mujer asume las diversas máscaras de su propia condición y habla desde allí, desde allí amplía la crónica de una aventura y un destino, que corre atado a ángeles y demonios y toca el éxtasis y el pecado, sirve de instrumento a la revelación" (p. 380). De esta obra, José Manuel Arango (2000), ese maestro que manejaba los silencios con tanta sabiduría, dijo que es "una galería de máscaras que la autora se prueba para reconocerse. Que quiere ser mudable como la luna" (p. 5). Y esto lo afirmó precisamente en la presentación del tercer libro publicado por la autora, La cicatriz del nacimiento, el cual él definió como una obra del desarraigo y de la soledad, pero también como una evidencia de que la autora "lleva ya andado buen trecho de ese camino a la interioridad" (p. 5). Este poema sintetiza muy bien la naturaleza de aquel libro: nas modificaciones para publicarlo nuevamente en el libro de Gloria Posada Bajo el cielo. Antología poética 2011-1985, con prólogo, selección y notas de Adolfo Castañón, publicado en México por la Universidad Veracruzana, en 2013. 
Polvo y luz

El día del alumbramiento

Engendra

la sombra de la agonía (Posada, 2000, p. 14).

En 2006 aparecería Naturalezas, volumen que reúne poemas escritos entre 1997 y 2005. Estas páginas son testimonio sobre la experiencia de los movimientos de la naturaleza, desde los más sutiles, como el que presenciamos cuando "Un aleteo restaura el aire / Pájaros retornan” (Posada, 2013, p. 80), hasta los movimientos del globo terráqueo, o el resurgir después de la tragedia: "Un nuevo día / y una casa en las montañas / se erige después del derrumbe” (p. 100). Movimientos que siempre tienen sus resonancias en lo más íntimo del ser humano. Adolfo Castañón (2013) afirma que en Naturalezas

[...] se da un registro del mundo, sus circunstancias, efectos y momentos: pulcro, limpio, como lavado de la persona, del yo, del sentimentalismo que es superado y trascendido por una observación impersonal que, en definitiva, solo admite el "nosotros" y no se limita a un principio de solidaridad, sino de "orden". Todo lo por fuera del "nosotros" parece excluido de esta mirada de águila real que mide naturalezas desde una altura en cuyo aire el mundo busca su ser, cifra y esencia (pp. 18-19).

En 2013, en México, apareció Bajo el cielo. Antología poética 2011-1985, que reúne gran parte de la obra de Gloria Posada, incluyendo sus obras inéditas, y que se convierte en un reconocimiento a su creación poética.

Y está su libro inédito Lugares, con poemas escritos entre 1999 y 2011. Una obra sobre la cual el crítico y escritor Julio Ortega (2013) dice:

La reflexión sobre lo visto es también un pensamiento sobre lo no visto, una pregunta por la naturaleza fugaz y el sentido duradero del mundo en el lenguaje. Como ese colibrí, "corazón de fuego", que late en una de sus páginas, estos poemas circulan en un espacio abismado, afirmando e interrogando, admirando y cuestionando; son un inventario afectivo, tan lírico como crítico (p. 369).

Antes de avanzar en el diálogo con la autora, es importante recordar que Gloria se graduó en Antropología y en Artes Plásticas; como artista también tiene una larga trayectoria, incluyendo premios y exposiciones nacionales e internacionales; y precisamente en su poesía la mirada de la antropóloga se cruza con los trazos de la artista, para reunir en sus versos un diálogo sobre algunos de los asuntos más profundos del ser humano, donde también intervienen de manera permanente los volúmenes, los colores, los claroscuros y las perspectivas. En otras palabras, la artista y la antropóloga se trenzan de manera permanente con la poeta en sus versos, en muchos de los cuales 
podemos presenciar también el dolor y la desolación de quien ha vivido y sufrido las violencias y las tragedias en una ciudad como Medellín, y que también ha conocido tantas historias de las miserias y el desarraigo emanados del conflicto armado que durante tantos años ha desangrado a Colombia. En sus poemas hay registros de todas estas tragedias, pero también del amor, de la vida y de la esperanza.

Gloria, empecemos con un asunto biográfico. En el libro Bajo el cielo. Antología poética 2011-1985, publicado en México en 2013, encontramos esta dedicatoria: "A mi padre Ricardo Posada / sangre, cuerpo y palabra / que soy". Esta dedicatoria da pie para preguntar sobre don Ricardo y pedirle que nos cuente lo significativo que él ha sido en su vida.

Bueno, es que yo desde niña tuve un fuerte nexo afectivo con mi padre, y él ha estado presente como un eje de mi vida a lo largo de los años. Mi madre murió cuando yo tenía 16 años, y en toda mi infancia, por sus enfermedades, no logré crear un vínculo con ella, siempre fue una mujer muy distante conmigo.

En mi paso del colegio a la universidad, mi padre nunca criticó mi decisión de estudiar antropología, de estudiar artes plásticas, ni tampoco ha cuestionado mis obras ni mis textos, siento que siempre ha respetado mis decisiones, e incluso cuando viví en Bogotá ocho años, me guardó mis obras en su casa. Él ha sido un gran apoyo en un proceso que no es fácil para nadie, querer ser artista, querer ser escritora.

¿Cómo se inició en la poesía? ¿Fue una lectora precoz? ¿Qué la llevó a interesarse por el oficio de escribir versos? Cuéntenos un poco de ese proceso inicial. Pues en mi casa no había muchos libros, a mí me gustaba mucho leer, pero no tenía muchas opciones, incluso cuando tenía como once años me puse a leer la Biblia porque era un libro que sí estaba en la casa, y mi hermano, que es mayor, me regañó porque desde sus tendencias ideológicas no le parecía adecuado, y para él, ese libro que han valorado tantos escritores en el mundo, era una superchería...

En mi adolescencia tuve amigos que me prestaban libros y también mi padre empezó a comprar la colección de literatura de la editorial Oveja Negra. Mi relación con la poesía fue más tardía, porque el acceso que tuve a ella en el colegio y en mi casa era muy limitada, y en muchos casos solo eran sonetos recitados que se presentaban en los actos cívicos escolares. Cuando entré a la universidad, conocí a compañeros que 
amaban la poesía y a través de ellos empecé a conocer a autores más contemporáneos, y empecé a leer intensamente ese género, y tomé la decisión de escribir poesía, y por eso estudiarla fue mi estrategia fundamental.

\section{¿Hay algún maestro, algún autor o algún mentor que haya jugado un rol pre- ponderante en su formación?}

Los primeros maestros son los escritores y artistas significativos de toda la historia de la literatura y del arte en diferentes sociedades y culturas, incluidos los libros, esculturas, pinturas y lugares que documentan una relación con lo sagrado, una cosmogonía. Por supuesto, varios de mis profesores en la Universidad de Antioquia y en la Universidad Nacional fueron muy importantes. Como artista, Luis Fernando Valencia fue un interlocutor y crítico significativo que apoyó mucho mi trabajo, escribió varios análisis sobre mis acciones urbanas y fue el curador de mi primera exposición individual "Obra en la tierra”, en la sala de arte de Suramericana, en 1993. Juan Alberto Gaviria también fue un curador fundamental para la realización de varios proyectos urbanos.

En el ámbito de la antropología, la profesora Aida Gálvez fue una mentora trascendental en mi vida. Con ella recorrí en varias ocasiones el cañón del Río Cauca a finales de la década de 1980 y en la década de 1990. Por ella conocí a diferentes comunidades que después fueron desplazadas por la represa Hidroituango; de esta manera llegué a un país que desde mi casa en Medellín había sido inaccesible.

Finalmente, como yo no estudié académicamente Literatura o Filosofía y Letras, en la Universidad de Antioquia busqué a varios profesores que eran un referente muy importante en la ciudad y se convirtieron en críticos e interlocutores muy significativos para mí: Elkin Restrepo y Luis Fernando Macías. Y cuando Vosotras fue finalista en el Premio Nacional de Poesía Eduardo Cote Lamus bajo la lectura de los jurados Fernando Charry Lara, Miguel Méndez Camacho y Juan Manuel Roca, este último apoyó mucho mi trabajo, difundiéndolo en el ámbito nacional, en el Magazín Dominical de El Espectador, como lo hizo con otros escritores que siempre han visto en él una figura tutelar. La labor de apoyo de Juan Manuel Roca a los poetas jóvenes del país ha sido fundamental para abrirles un espacio en un medio que, por ejemplo en Medellín, era eminentemente masculino y con luchas de poder bastante complejas... 


\section{¿Qué tan influyente ha sido su formación como antropóloga en su poesía y en su obra plástica?}

Mis estudios de antropología en la Universidad de Antioquia sensibilizaron y educaron la mirada sobre el paisaje, el entorno, los lenguajes, los símbolos y el mundo. Todos estos ámbitos constituyen y fundamentan la relación con las artes plásticas y con la poesía.

En la antropología confluyen las concepciones culturales de la naturaleza, los mitos, el cuerpo, la casa y la ciudad. Por todo ello, yo siempre me he concebido como una antropóloga que escribe poesía y hace arte.

\section{¿Qué ha significado para usted habitar esta Medellín, en su permanencia y en las mutaciones que nos ha tocado presenciar?}

Medellín es la ciudad donde nací, es mi territorio existencial, la ciudad donde crecí, de donde parto y a donde siempre vuelvo... De mi infancia a mi juventud, me tocó el paso de tener una vida barrial a ser testigo de las violencias ocasionadas por múltiples guerras, y no solo eso, sino padecer una concepción de progreso que ha destruido el patrimonio arquitectónico y ambiental bajo una relación con el territorio de dominio, lucro y desconocimiento de las significaciones históricas.

\section{¿Qué fue primero para usted, la poesía o las artes plásticas?}

Primero inicié la búsqueda de la poesía. Para hacerlo no necesitaba estar matriculada en una carrera universitaria, solo tenía que conocer la historia de la literatura, ir a bibliotecas, prestar libros, y tener algunos interlocutores que leían mis textos y les hacían críticas muy puntuales. Con las artes plásticas el proceso fue un poco más académico: yo empecé a estudiar en la Universidad Nacional en 1987, y llegué con todos los miedos por tener una educación artística muy poco fundamentada durante la secundaria. Entonces solo en la universidad conocí otros lenguajes más allá de los tópicos comunes de la pintura, el dibujo o la escultura, y empecé a entender que el arte no se basa en el talento o la inspiración, sino que es un trabajo de investigación y un proceso de conceptualización y de compromiso muy fuerte.

En sus instalaciones, en sus esculturas se encuentra poesía, y en sus versos, trazos pictóricos, perspectivas, profundidad de campo, en fin, se advierte tam- 
bién un ejercicio plástico. ¿Cómo vive ese vaivén entre las distintas manifestaciones? ¿Es consciente de esos procesos sinestésicos en su ejercicio creativo? Siento que todo parte de la mirada, de tratar de descifrar imágenes, sonidos, palabras, y buscar, por medio de diferentes lenguajes, una transfiguración. Ante la necesidad de comunicarme, el arte y la poesía han sido mi búsqueda de interlocución, mi forma de enviar mensajes, de establecer nexos con la tierra, el cielo, la naturaleza; de sentirme parte de ellos, y por supuesto, a veces el silencio es otra manera de ser, de estar...

\section{En su obra plástica y también en su poesía están presentes el dolor y el desa- rraigo que sufren tantos colombianos, del cual usted también ha sido testigo, como artista sensible, pero también como antropóloga.}

Tuve la oportunidad de realizar, como estudiante de antropología, trabajos de campo en Sabanalarga, Antioquia, en las materias de etnografía y de arqueología a cargo de las profesoras Aida Gálvez y Sofía Botero, cuando Hernán Henao era el director de la carrera en la Universidad de Antioquia, a finales de la década de 1980. Esos recorridos los continué con Aida en diferentes veredas del cañón del Río Cauca en compañía de los servicios de salud que conseguimos para los campesinos.

En años posteriores, las masacres cometidas por grupos paramilitares produjeron el desplazamiento de cientos de personas hacia la cabecera municipal y hacia Medellín, con graves problemas sociales para la población. Y los antropólogos liderados por Aida Gálvez volvimos a Sabanalarga para realizar un acompañamiento a la comunidad.

Las obras Mapa, Territorio sumergido y Fragmentos, exhibidas en la exposición individual Mapas y Fragmentos (2000), curada por José Roca, surgen de todos estos conflictos generados por el megaproyecto de la Hidroeléctrica Ituango. Y fue precisamente Aida quien me sugirió en años anteriores que sería importante que como artista visibilizara todas estas situaciones...

Como lector y como espectador se puede percibir o intuir confluencias entre sus distintas vertientes. Pero para no especular es mejor escucharlo de su propia voz: ¿cómo confluyen la poesía y las expresiones plásticas en su visión de nuestro mundo contemporáneo?

Tanto en las artes plásticas como en la literatura, yo he trabajado con la naturaleza, el paisaje, el territorio, lo urbano. He tratado de tener una contemplación consciente de 
estos contextos, de estos espacios y tiempos donde confluyen el pasado y el presente. Pero cada vez me duelen más las problemáticas sociales de Colombia, uno de los países con mayores índices de pobreza, desigualdad, corrupción, violencia y falta de acceso a la salud, a la educación y al empleo. Y a veces, como artistas o escritores nos sentimos impotentes para crear en medio de estas tragedias, para tener una voz y una mirada que señalen todo esto para visibilizarlo, nombrarlo, y tal vez exorcizarlo con nuestro trabajo...

A propósito de una intervención artística que usted hizo en 1992 con cien personas, con el título Los caminos que bemos becho caminando, en conmemoración de los 125 años de la Universidad Nacional, y que era una intervención de los caminos, como una manera de representar la huella que todos han dejado en la Universidad, ¿cómo son las huellas que estamos dejando hoy en Colombia? ¿Qué caminos encontrarán las generaciones venideras?

Pues yo espero que las huellas que estamos dejando sean de renovación, de una visión crítica para construir un nuevo país. Creo que hay otra conciencia política de lucha por los derechos sociales, de reivindicación frente a los errores del pasado. También existe una lucha ambiental que era muy limitada en las generaciones anteriores. Entonces estamos asistiendo a una expansión de la conciencia en muchos sentidos. Ojalá quienes se oponen a la justicia y a la equidad no sigan obstaculizando que $\mathrm{Co}^{-}$ lombia sea un país mejor para todos.

Usted en sus obras ha estado rastreando huellas, huellas, huellas... ¿Cuáles son las huellas más marcadas que le han quedado en su vida?

Quiero hablar principalmente de las huellas positivas, por las cuales tengo un gran agradecimiento. Poder estudiar Artes Plásticas y Antropología, y hacer un Magister en Estética. Encontrar a autores como Safo, Emily Dickinson, Fernando Pessoa, César Vallejo, Jorge Luis Borges, Alejandra Pizarnik, entre muchos otros... Ver el mar por primera vez en la infancia. Materializar Los caminos que hemos hecho caminando en 1992 con más de cien personas en la Universidad Nacional de Medellín. Hacer Ser ángel por un día en 1995 con cien niños trabajadores de Bogotá. Ganar el Premio Nacional de Poesía Joven de Colcultura en 1992 con el libro Oficio Divino, bajo la evaluación de los jurados Jaime García Maffla,Juan Manuel Roca y Giovanny Quessep. Conocer 
el cañón del Río Cauca y sus comunidades antes de la construcción de la represa Hidroituango, de las masacres y del ecocidio. Vivir en la Comuna 13 desde 1999, antes de las guerras entre diferentes grupos armados, estar en mi casa en medio de todos los fuegos y huir desplazada por la Operación Orión. Visitar La Alhambra y la Mezquita de Córdoba. Ver la obra de El Bosco y de Fray Angélico en el Museo E1 Prado. Ser reconocida por el Proyecto Victimas de la revista Semana en 2013 con la obra Mapa, seleccionada como una de las ocho obras emblemáticas de las relaciones arte-violencia en Colombia en las últimas décadas. Obtener el 7o Premio Memoria, modalidad Escultura Memorial, en los Premios Nacionales de Cultura de la Universidad de Antioquia. Y podría seguir enumerando hechos que han marcado mi vida por sus diferentes significaciones...

En los Premios Nacionales de Cultura Universidad de Antioquia 2020 le fue concedido el premio Memoria, modalidad Escultura memorial, por la obra $\mathrm{La}$ Casa deshecha, en homenaje a las personas que tienen que enfrentar el destierro y el desarraigo. Cuéntenos en sus palabras en qué consiste esta obra, y sobre todo su reflexión respecto a esta visión tan dramática que viven tantos colombianos. El proyecto surge del concepto de la casa como representación del habitar, pero paradójicamente lo que $L a$ Casa deshecha muestra es que las problemáticas del desplazamiento forzado en Colombia hacen imposible tener un arraigo, una morada. Y entonces la casa se convierte en memoria de un territorio desaparecido.

Por todo esto, la construcción se presenta derribada sobre la tierra y su tipología arquitectónica se basa en la tradición de las comunidades desplazadas de Urabá. En el interior de la puerta, que se abre con un sensor de movimiento, hay una excavación de un área ocupada por una mesa con sus dos sillas, y la cobertura en la superficie es con un vidrio templado transparente que podrá ser recorrido por los espectadores.

\section{Uno siente que usted con su obra se empeña en desacomodar al espectador y} al lector, en obligarlo a replantearse su forma de mirar.

Creo que por ser artista plástica tengo una conciencia del espacio distinta a la relación de los escritores con esta dimensión. Cuando estudié en la Universidad Nacional, constantemente recibí señalamientos y críticas sobre los nexos de mis propuestas con el espacio, y eso fue muy importante para mí. El espacio es arriba, abajo, a los lados, 
transversal, y cambia la percepción cuando es recorrido, y la relación también es distinta según la distancia del observador. Cuando materializo mis propuestas plásticas, escribo y reviso mis textos, trato de mirarlos desde muchos puntos de vista.

¿Cómo describiría usted la ciudad real, la ciudad que ha gozado y sufrido a lo largo de sus vivencias en Medellín? ¿Y podría decirnos ahora cómo sería la ciudad soñada?

Pienso que hay una ciudad real construida día a día por los urbanistas, por los arquitectos, por la planeación metropolitana, por los habitantes, por la manera de residir, pensar e imaginar el territorio. También existe una ciudad con grandes exclusiones, problemáticas de convivencia, pobreza y educación. Y en medio de todo ello, la ciudad soñada sería aquella en que la construcción de comunidad, de saberes, de democracia, de oportunidades y de respeto por la vida y la naturaleza fueran posibles.

Tanto la ciudad real como la ciudad soñada se encuentran en la obra de artistas, escritores y arquitectos de Medellín, y por ello sus trabajos son muy significativos para entender las distintas configuraciones históricas que caracterizan diferentes periodos.

\title{
En 2016, cuando se dio la firma de los Acuerdos de Paz en Colombia, usted escribió un epitafio para la guerra:
}

\author{
Tierra de luto \\ Cuánto aire consume la palabra guerra \\ Cuántas voces preguntan de dónde viene \\ y a dónde va... \\ Su fuego se extingue \\ como aliento transfigurado en rocío \\ en un territorio que exorciza \\ los nombres del mal \\ Todas las lágrimas se unen \\ Los ríos se llevan la muerte \\ en caudal sin retorno \\ que fluya hacia el país \\ de la espera
}

Después de estos cuatro años transcurridos desde la firma de aquel Acuerdo, ¿qué piensa sobre lo que está pasando hoy en este país que sigue sembrado de odios y de violencias?

El epitafio Tierra de luto lo escribí para el evento "Descanse en paz la guerra”, organizado por la Biblioteca Nacional, la Casa de Poesía Silva y el Ministerio de Cultura. 
En ese momento teníamos la esperanza de un nuevo país sin el lastre de la violencia que ha marcado su historia. Desafortunadamente, son muchos los enemigos de la paz, y es decepcionante ver cómo muchos grupos conservan sus privilegios y buscan a toda costa la impunidad de sus crímenes. Por supuesto, la justicia para las víctimas y el cumplimiento de los Acuerdos se ha obstaculizado.

\section{¿Cómo percibe usted el ámbito editorial para la creación poética hoy en} nuestro entorno, y qué visión tiene frente al quehacer artístico en la ciudad y a las dinámicas de este, tan mediados, por supuesto, por la institucionalidad? Hay un trabajo editorial muy dinámico, divulgando la obra de muchos autores. Pero no podría profundizar en esta respuesta; desde el año 2000 yo no publico en Colombia: tuve una experiencia editorial muy traumática con mi libro Vosotras en 1993 y por eso me alejé siete años de la publicación de mis poemarios y los dejé guardados e inéditos.

Mis últimos libros han sido publicados en México y en España; he tratado de publicar aquí, he mandado mis libros a algunas editoriales, pero han sido rechazados. Las ediciones de los libros Naturalezas (2006), Bajo el cielo. Antología poética 20111985 (2013), y Aire en luz. Muestra de poesía 2016-1985 (2017) han sido posibles por el apoyo que le han dado a mi trabajo los críticos literarios latinoamericanos Adolfo Castañón y Julio Ortega.

Respecto al quehacer artístico en la ciudad mediado por la institucionalidad, es un poco triste ese panorama desde hace varias décadas. Hay personas que no se sabe el porqué tienen unos cargos de gran responsabilidad con la cultura y las artes, y se asumen como los dueños vitalicios de ciertos espacios e instituciones; esos funcionarios están en una zona de confort, pero para los artistas es un ámbito desolador. También hay personas que llegan a la ciudad de otros lugares, pero no conocen el arte antioqueño ni les interesa conocerlo, y cuando supuestamente hacen curadurías sobre Antioquia, están llenas de limitaciones conceptuales e históricas...

Y en medio de todo esto uno se pregunta: ¿quiénes son los dueños de la cultura y de las artes en Medellín? Finalmente, la respuesta a la que uno llega después de más de treinta años en este medio es que existe una burocracia cultural que asume que como funcionarios no están al servicio de la comunidad y de los artistas, sino que, por el contrario, son la comunidad y los artistas quienes deben estar al servicio de ellos... 


\section{¿Y qué fue lo que pasó con Vosotras?}

Vosotras fue el libro que me dio a conocer como poeta en el país; en su proceso de trabajo lo sometí a la lectura crítica de muchas personas, y esa interlocución fue muy importante para mí. Creo que ese libro me confrontó como mujer, como poeta joven y prácticamente inédita, y como una persona que provenía de otras disciplinas y que fue recibida de una manera muy generosa por los poetas del país.

Yo trabajé mucho el manuscrito y lo presenté al comité de la Colección Autores Antioqueños de la Gobernación de Antioquia, y fue aprobado para su publicación en 1993. Tiempo después me encontré con Víctor Gaviria y Helí Ramírez, escritores que habían sido publicados en la colección, y cada uno por su lado me dijo que tuviera mucho cuidado con Vosotras porque las publicaciones de ellos habían salido llenas de erratas, y por eso más que una alegría, se convirtieron en una tragedia, y me aclararon que ellos habían pensado que el editor estaría supervisando todo el proceso, pero que no fue así... Por tal motivo, a pesar de que en esa época yo no tenía computador, busqué la ayuda de Carlos Enrique Sierra, quien consiguió ayuda en una corporación para trabajar allá los fines de semana; yo le dicté a Carlos el libro, él lo digitó y yo revisé la impresión en mi casa para posteriormente corregir con Carlos algunos errores de digitación. El proceso fue demorado porque el manuscrito era extenso. Entonces le entregué al editor el disquete con todos los poemas, pensando que así saldrían bien; sin embargo, quise revisar el diseño que hicieron, y al leer los poemas vi que no era la misma versión que había pasado en el disquete; el libro estaba lleno de errores, y me tocó volver a revisar todo, corregir los textos con la empresa que contrataron para la publicación, y, por supuesto, el trabajo inicial se perdió porque al parecer nunca les entregaron el disquete a ellos...

Yo tenía 25 años, y sentí que publicar es una labor muy ardua y que así se haga lo que se haga, hay personas que obstaculizan todo el proceso y no hacen su trabajo con rigor. Y aún hoy me pregunto cuál era la labor de ese editor, e incluso me da miedo leer otros libros de esa colección: ¿será que los libros de grandes autores antioqueños muertos también están llenos de errores? Una de las últimas veces que vi a ese editor fue hace casi dos décadas en el archivo fotográfico de la Biblioteca Pública Piloto; yo hacía una investigación sobre patrimonio en Medellín y él entró intempestivamente fumando un cigarrillo... Al parecer, para él la nicotina no afectaba los archivos... 
A propósito de este poema, publicado en su antología Bajo el cielo...

\author{
Al grito de guerra \\ ningún varón \\ se quedará en la aldea \\ ¿Qué haremos las mujeres \\ con el amor \\ mientras los hombres \\ convocan la muerte?
}

Qué visión tiene usted de la guerra, y cómo la ha vivenciado a lo largo de su vida. Ese poema pertenece al libro inédito Periodo de sombra, que empecé a escribir en 1991. Algunos de estos poemas fueron publicados en el suplemento cultural Imaginario del periódico El Mundo de Medellín, el 23 de marzo de 1996, al igual que en la Antología de la Poesía Colombiana, compilada por Rogelio Echavarría y editada por el Ministerio de Cultura de Colombia y el Áncora Editores en 1997. Y por supuesto, una muestra más representativa del libro forma parte de la antología Bajo el cielo, editada por la Universidad Veracruzana en México en 2013.

Mi vivencia de la guerra fue inicialmente en los libros de historia, en el cine, la literatura y en las noticias de lo que sucedía en el mundo, pero durante la escritura de Periodo de sombra la guerra en Colombia se acrecentó, y cada vez fue más cercana a mí, primero con la guerra del narcotráfico que creó un clima de zozobra en todo el país, y después con mi vivencia de las confrontaciones en la Comuna 13 en Medellín, donde residí en la urbanización San Michel entre 1999 y 2004. Como testimonio, escribí “En el vecindario de la Comuna 13", difundido en los periódicos El Tiempo, el 31 de agosto de 2003, en Colombia, y en La Jornada Semanal, el 26 de octubre de 2003, en México, entre otras publicaciones...

Desafortunadamente, la violencia y la guerra nunca han cesado, y la hemos vivido con diferentes intensidades en las ciudades y en las zonas rurales.

En su libro Vosotras, los poemas se convierten en una invocación de mujeres de distintas épocas, sean de la historia, de la religión, la literatura o la mitología, por ejemplo. ¿Cómo ve esta especie de revolución mediática que estamos presenciando actualmente, a propósito de las reivindicaciones de las mujeres? Las luchas por los derechos de las mujeres han existido desde hace varios siglos; con las redes sociales pueden visibilizarse más, y todos hemos asistido a la construcción 
de una comunidad en constante interacción que expande los límites de su conciencia y de sus luchas. Lo que me preocupa es que a veces hay unas expresiones de fanatismo que no son coherentes con la convicción del respeto por los derechos de los seres humanos, sin importar el género...

Gloria: usted es una mujer de mediana edad, muy joven podríamos decir para su trayectoria y para los logros cosechados en sus diversas expresiones artísticas. ¿Cuáles son sus sueños hoy? ¿Hacia dónde quiere seguir en sus búsquedas?

Bueno, gracias por esa valoración de mi trabajo. Hace unas décadas, lo más importante para mí era mi trabajo poético y plástico; pero con los años, le he dado más valor a otros lenguajes, al lenguaje de la dignidad, de la honestidad y la justicia. Me duele profundamente la situación del país, el ecocidio del Río Cauca, las víctimas de Hidroituango, los Falsos Positivos, la corrupción, el hambre, lo difícil que es el acceso a la educación para muchas personas. Yo quiero seguir siendo artista y poeta, pero crear en medio del dolor y la devastación ya no es suficiente para mí, y cada vez es más difícil porque la impotencia de no lograr hacer nada ante los malvados, me rebasa. Y además, a lo largo de los años también he conocido a una burocracia cultural que en muchos casos maltrata y destruye a los artistas. Entonces construir una voz, unos símbolos, una transfiguración de la realidad en medio de todo esto se ha vuelto una situación muy compleja para mí, que en muchos años me ha enfrentado al escepticismo, al silencio, al ostracismo...

\section{Referencias bibliográficas}

Arango, J. M. (2000). Presentación. En G. Posada. La cicatriz del nacimiento (pp. 5-8). Medellín: Editorial El Propio Bolsillo, colección Ojo Editorial, 15.

Castañón, A. (2013). Prólogo. Hacia el poema. En G. Posada. Bajo el cielo. Antología poética 2011-1985 (pp. 9-31). México: Universidad Veracruzana.

García Maffla, J. (2013). Oficio Divino. En G. Posada. 2013. Bajo el cielo. Antología poética 2011-1985. (pp. 381-382). México: Universidad Veracruzana.

Ortega, J. (2013). Lugares. En G. Posada. Bajo el cielo. Antología poética 2011-1985 (pp. 369-370).

México: Universidad Veracruzana. 
Posada, G. (2000). La cicatriz del nacimiento. Medellín: Editorial El Propio Bolsillo, colección Ojo Editorial, 15.

Posada, G. (2013). Bajo el cielo. Antología poética 2011-1985. México: Universidad Veracruzana.

Restrepo, E. (2013). Vosotras. En G. Posada. Bajo el cielo. Antología poética 2011-1985 (pp. 379-380). México: Universidad Veracruzana. 